\title{
Machine learning for prediction of immunotherapy efficacy in non- small cell lung cancer from simple clinical and biological data
}

Sébastien Benzekry 1, *, Mathieu Grangeon 2, *, Mélanie Karlsen ${ }^{1}$, Maria Alexa 1 , Isabella Bicalho-Frazeto ${ }^{1}$, Solène Chaleat ${ }^{2}$, Pascale Tomasini 2,3, Dominique Barbolosi ${ }^{1}$, Fabrice Barlesi ${ }^{3,4}$, Laurent Greillier ${ }^{1,2}$

1. COMPutational pharmacology and clinical Oncology Department, Inria Sophia Antipolis - Méditerranée, Cancer Research Center of Marseille, Inserm UMR1068, CNRS UMR7258, Aix Marseille University UM105, Marseille, France

2. Multidisciplinary Oncology and Therapeutic Innovations Department, Assistance Publique - Hôpitaux de Marseille, Aix Marseille University, Marseille, France.

3. Aix Marseille University, CNRS, INSERM, CRCM, Marseille, France

4. Gustave Roussy Cancer Campus, International Center of Thoracic Cancers, Université Paris-Saclay, Villejuif, France.

${ }^{*}=$ these authors contributed equally

The authors declare no conflict of interest.

Social media handles:

Authors : @SBenzekry, @barlesi, @LGreillier

Institutions : @aphm_actu, @inria_sophia,@crcm_marseille

\section{Highlights:}

- Machine learning applied to a large set of NSCLC patients could predict efficacy of immunotherapy with a $69 \%$ accuracy using simple routine data

- Hemoglobin levels and performance status were the strongest predictors and significantly associated with DCR, PFS and OS

- Neutrophils-to-lymphocyte ratio was also associated with outcome

- Benchmark of 8 machine learning models 
medRxiv preprint doi: https://doi.org/10.1101/2021.11.30.21267064; this version posted December 2, 2021. The copyright holder for this preprint (which was not certified by peer review) is the author/funder, who has granted medRxiv a license to display the preprint in

\section{ABSTRACT}

\section{Background}

Immune checkpoint inhibitors (ICls) are now a therapeutic standard in advanced nonsmall cell lung cancer (NSCLC), but strong predictive markers for ICls efficacy are still lacking. We evaluated machine learning models built on simple clinical and biological data to individually predict response to ICls.

\section{Methods}

Patients with metastatic NSCLC who received ICI in second line or later were included. We collected clinical and hematological data and studied the association of this data with disease control rate (DCR), progression free survival (PFS) and overall survival (OS). Multiple machine learning (ML) algorithms were assessed for their ability to predict response.

\section{Results}

Overall, 298 patients were enrolled. The overall response rate and DCR were $15.3 \%$ and $53 \%$, respectively. Median PFS and OS were 3.3 and 11.4 months, respectively. In multivariable analysis, DCR was significantly associated with performance status (PS) and hemoglobin level (OR 0.58, $p<0.0001$; OR 1.8, $p<0.001$ ). These variables were also associated with PFS and OS and ranked top in random forest-based feature importance. Neutrophils-to-lymphocytes ratio was also associated with DCR, PFS and OS. The best ML algorithm was a random forest. It could predict DCR with satisfactory efficacy based on these three variables. Ten-fold cross-validated performances were: accuracy $0.68 \pm 0.04$, sensitivity $0.58 \pm 0.08$; specificity $0.78 \pm 0.06$; positive predictive value $0.70 \pm 0.08$; negative predictive value $0.68 \pm 0.06$; AUC $0.74 \pm 0.03$.

\section{Conclusion}

Combination of simple clinical and biological data could accurately predict disease control rate at the individual level.

Keywords: Blood counts, lung cancer, response, survival, prediction, machine learning 
medRxiv preprint doi: https://doi.org/10.1101/2021.11.30.21267064; this version posted December 2, 2021. The copyright holder for this preprint (which was not certified by peer review) is the author/funder, who has granted medRxiv a license to display the preprint in It is made available under a CC-BY-NC-ND 4.0 International license .

\section{INTRODUCTION}

Immune checkpoint inhibitors (ICls) are now a therapeutic standard in several advanced cancers, particularly in stage IV non-small cell lung cancer (NSCLC) without genetic alteration ${ }^{1,2}$. The development of $\mathrm{ICls}$ is leading to treat an increasing number of patients with these expensive drugs. Even if the overall response rate is higher with ICls than chemotherapy, it is equal to about $20 \%$ for ICls in monotherapy ${ }^{2}$. Consequently, there are still 4 patients out of 5 with no response to single agent $\mathrm{ICI}$. Thus, identification of predictive markers for ICls efficacy is an important unmet medical need.

Biologically, ICls mechanism of action rely on the immune system and tumor micro-environment. Tumor-infiltrating lymphocytes (TILs) are known to have different effects on survival ${ }^{3}$. Blood counts may be a surrogate marker of these TILs and reflect inflammation and adaptive immune response in lung cancer ${ }^{4}$. In this respect, analysis of blood counts before the start of ICls showed some interesting correlation with response. In a meta analysis ${ }^{5}$, particularly in melanomas treated with Ipilimumab, a higher lymphocyte count and relative lymphocyte count predicted better overall survival (OS), as for a higher eosinophil count and lower neutrophil count. Neutrophil to lymphocyte ratio (NLR) at baseline has also been investigated, and its decrease was associated with better OS, progression-free survival (PFS) and response ${ }^{6}$. The derived NLR (dNLR = absolute neutrophils count / [white blood count - absolute neutrophils count]) is another ratio which has already been an alternative to NLR in melanomas ${ }^{7,8}$ and metastatic colorectal cancer ${ }^{9}$. Furthermore, for lung cancer, in a Chinese meta-analysis published in $2016^{10}$, high levels of platelet to lymphocytes ratio (PLR) at baseline were associated with poor OS and PFS, but in all types of treatment. Specifically for NSCLC treated by ICls, a study showed that a score combining dNLR greater than 3 with elevated LDH was correlated with worse outcome for ICls ${ }^{11}$. Furthermore, an Italian study in NSCLC patients treated by ICls ${ }^{12}$ showed that low NLR and low PLR at baseline were associated with development of immune related adverse events (IRAEs), and low NLR was associated with better outcomes (OS, PFS). However, a comprehensive analysis of all classical blood markers for prediction of efficacy in a large number of patients is still lacking ${ }^{13}$. 

medRxiv preprint doi: https://doi.org/10.1101/2021.11.30.21267064; this version posted December 2, 2021. The copyright holder for this
preprint (which was not certified by peer review) is the author/funder, who has granted medRxiv a license to display the preprint in It is made available under a CC-BY-NC-ND 4.0 International license.

In the era of precision medicine, machine learning (ML) has recently developed as an alternative to classical statistical analysis ${ }^{14}$. The main difference is that statistical analysis focuses on inference and association between variable(s) and outcome(s), while ML puts emphasis on predictive performances only ${ }^{15}$. In oncology, ML has demonstrated great success for prediction from large-dimensional 'big' data, such as genomics or imaging ${ }^{14}$. Nevertheless, such data science methods also have relevance to establish predictive models from smaller sets of variables ${ }^{16}$. In addition, successes have mostly been limited to diagnosis and prognosis but seldom for predictive applications in a clinical oncology context (i.e., for therapeutic decision).

We hypothesized that ML could be useful to accurately predict the efficacy of ICls in NSCLC patients. The present study aimed to develop a ML model for the selection of patients which could benefit from treatment with ICls, from simple clinical and biological data. 
medRxiv preprint doi: https://doi.org/10.1101/2021.11.30.21267064; this version posted December 2, 2021. The copyright holder for this preprint (which was not certified by peer review) is the author/funder, who has granted medRxiv a license to display the preprint in It is made available under a CC-BY-NC-ND 4.0 International license.

\section{MATERIALS AND METHODS}

\section{Patients}

In this observational monocentric retrospective study, we analyzed data from all patients older than 18 years of age who were diagnosed with advanced NSCLC and who received at least 1 cycle of ICI (anti-PD-L1, anti PD-1 or anti-CTLA-4), alone or in combination (anti-PD(L)1 and anti-CTLA4) following a first cycle of non-ICI systemic therapy from April 2, 2013 to February 14, 2017. Patients were treated according to available guidelines.

The study protocol and retrospective data collection were approved by the Institutional Review Board of the French Society of Respiratory Diseases (Société de Pneumologie de Langue Française - SPLF), under reference number: CEPRO 2019007 and patients have signed an informed consent.

\section{Data}

Data were retrieved from electronic patient records. Clinical and epidemiological data (age, gender, tobacco status, asbestos exposure, performance status, body mass index), disease characteristics (histology, mutation status, TNM stage), treatment data (type, treatment line, toxicity), biological data (last blood count before first infusion of $\mathrm{ICI}$ ) and outcome data (response and survival) were collected. From the pre-treatment blood counts, we calculated the PLR, NLR, and derived NLR (dNLR) = absolute neutrophils count / (white blood count - absolute neutrophils count). Performance status was dichotomized into $<2$ or $\geq 2$.

Tumor response was assessed once every 2 months through computed tomography scans, according to the Response Evaluation Criteria in Solid Tumors, version 1.1.17 Definition of response here is the best response observed. Overall response rate (ORR) included patients with complete or partial responses. Disease control (DCR) included patients with complete, partial responses or stable disease. Overall survival was defined as the time from start of immunotherapy to death from any cause, censored at the date of last follow-up. Progression-free survival was defined as the time from start of immunotherapy to documented disease progression or death from any cause, censored at the date of last follow-up period. 
medRxiv preprint doi: https://doi.org/10.1101/2021.11.30.21267064; this version posted December 2, 2021. The copyright holder for this preprint (which was not certified by peer review) is the author/funder, who has granted medRxiv a license to display the preprint in

\section{Statistical Analysis}

In exploratory data analysis, two-tailed Student's t-tests were used for continuous variables and chi-squared tests for categorical variables. Association of clinical and biological data response was assessed using univariable and multivariable logistic regression, as implemented in the $g / m$ function of the $R$ software (version 3.6) ${ }^{18}$. Survival analyses of OS and PFS were performed using univariable and multivariable proportional hazard Cox's regression models ${ }^{19,20}$. Continuous variables were centered and scaled before these analyses.

\section{Machine Learning}

Feature selection was performed using feature importance given by a random forest classification algorithm applied on the entire data set (randomForest $R$ package, no tuning, 1,000 trees). Once sorted by mean decrease accuracy, incremental logistic regression models were built with increasing number of variables. The selected optimal set of features was the maximal one before observing a decrease in 10-fold crossvalidated accuracy. Predictive machine learning (ML) models were further built and assessed using repeated nested $k$-fold cross-validation with 5 repeats of 3 outer loops (to assess generalizability) containing each 5 repeats of 3 inner loops (to tune the models). Thus, 15 train and test sets were built to test the predictive performances. The models were implemented under the tidymodels framework in $R$ version 4.0.4 ${ }^{21}$. They included: logistic regression $(\mathrm{g} / \mathrm{m})$, random forest (ranger, 1000 trees), single layer neural network (2600 maximum number of weights), naïve Bayes, k-nearest neighbors ( $k k n n$, rectangular kernel function) and support vector machines (with linear, polynomial or radial basis kernel function). For each outer fold, models were tuned and trained on the train set and predictions were assessed on the test set. The decision tree was built using the rpart engine and tuned for hyper-parameters of tree depth, minimum number of data points required for further splitting $\left(\min \_n\right)$ and complexity parameter (cost_complexity), using a grid search and a 10 -fold cross-validation. The tree was then trained on the entire set. 
medRxiv preprint doi: https://doi.org/10.1101/2021.11.30.21267064; this version posted December 2, 2021. The copyright holder for this preprint (which was not certified by peer review) is the author/funder, who has granted medRxiv a license to display the preprint in It is made available under a CC-BY-NC-ND 4.0 International license .

\section{RESULTS}

\section{Patients and Disease Characteristics}

Overall, 298 patients treated with ICls for stage IV or relapsed NSCLC were retrieved from our database and analyzed. Patient and disease characteristics are summarized in Table 1. Regarding the treatments with ICls, $89 \%(n=266)$ of patients received an anti-PD-1 antibody, with $96.7 \%(n=286)$ patients being pretreated with chemotherapy prior to ICls. The report of blood counts values at start of treatment with ICls are reported in Table S1.

\section{Statistical Analysis}

\section{Response}

The DCR was $53.4 \%$ and ORR was $15.4 \%$. Exploratory data analysis was conducted for association of the considered variables with outcome (Figure 1). Significant associations were found for NLR $(p<0.001)$, derived NLR $(p<0.001)$, hemoglobin $(p<0.0001)$, leukocytes $(p<0.01)$ and neutrophils $(p<0.001)$. These results were confirmed by logistic regression analysis, with additional significance of (Table 2). However, in multivariable analysis, only hemoglobin and PS remained significant. They also remained significant in multivariable analysis controlling for possible additional confounding factors: sex, immunotherapy type and smoking status.

Survival analysis

Progression-free and overall survival are reported in Figure S1. The median PFS was 3.27 months (95\% Cl: 2.63 - 4.07) and median OS was 14.5 months $(95 \% \mathrm{Cl}$ : 8.8 - 15.5). Proportional hazard Cox regression confirmed association of hemoglobin and performance status with response. They were significantly correlated with PFS and OS, in univariable and multivariable analysis (Tables S2 and S3). They also remained significant in multivariable analysis controlling for possible additional confounding factors: sex, immunotherapy type and smoking status.

\section{Machine Learning}

The ML analysis was conducted for prediction of DCR (classification task) and comprised two steps. First, feature selection and then ML classification. The first step was conducted using random forest-based mean decrease in accuracy (Figure 2A) followed by selection of an optimal number of predictors (Figure 2B). The former 
medRxiv preprint doi: https://doi.org/10.1101/2021.11.30.21267064; this version posted December 2, 2021. The copyright holder for this preprint (which was not certified by peer review) is the author/funder, who has granted medRxiv a license to display the preprint in It is made available under a CC-BY-NC-ND 4.0 International license .

revealed hemoglobin level as the strongest predictor of DCR. The second strongest predictor was performance status, followed by NLR. Adding further predictors resulted in a decrease in the cross-validated accuracy of logistic regression models (Figure 2B). Thus, these three variables were selected for further inclusion in ML models.

Multiple machine learning models using this set of variables were then assessed for their predictive abilities of DCR (Figure 3 and Table 3 ). First, learning curves -which evaluate the models predictive abilities with increasing number of patients demonstrated that convergence to the optimal predictive power had been reached, for each model (Figure S2). Receiver-operator curves were similarly discriminant across the algorithms (Figure 3A), apart from k-nearest neighbors (knn) and the polynomial support vector machine (SVM) with poorer performances. Aside knn, mean areas under the curve ranged $0.72-0.74$ (Table 3). Similarly, precision (sensitivity) - recall (positive predictive value) curves were comparable (Figure 3B). Best accuracy was $68 \%$, achieved by the random forest model. Sensitivity was generally low (max 0.58 , random forest) while specificity was high $(0.73-0.94$, Table 3$)$. Best positive (naive Bayes, 0.72) and negative (random forest, 0.68) predictive values suggested good predictive power (Table 3). Altogether, the ML algorithms performances suggested the random forest algorithm as the most adequate, achieving highest score in the largest number of them (accuracy, area under the ROC curve, sensitivity and negative predictive value, Table 3 ) and exhibiting the smallest inter-score variability (Figure 3C).

A random forest algorithm being hard to interpret, we also trained a decision tree algorithm (Figure 3D). This confirmed performance status ( $<2$ versus $\geq 2$ ) and hemoglobin level (optimal threshold $13 \mathrm{~g} / \mathrm{dL}$ ) as the most important predictive variable. Then NLR, consistently with our random forest-based importance analysis. This tree could be useful for clinical decision at bedside. For instance, patients with patient status $<2$ and hemoglobin $\geq 13 \mathrm{~g} / \mathrm{dL}$ are predicted to have an $83 \%$ chance of disease control. 
medRxiv preprint doi: https://doi.org/10.1101/2021.11.30.21267064; this version posted December 2, 2021. The copyright holder for this preprint (which was not certified by peer review) is the author/funder, who has granted medRxiv a license to display the preprint in It is made available under a CC-BY-NC-ND 4.0 International license.

\section{DISCUSSION}

The selection of patients who will benefit from ICls therapies is crucial in the era of precision medicine, in order to develop new strategies for those patients who are not likely to respond from current strategies. Clinical examination and blood counts are easily acquired, but their predictive power in combination remains to be determined. While classical statistical methods are appropriate and have been employed for determination of association with outcome ${ }^{11,22}$, ML techniques are more adapted for prediction tasks. Therefore, we decided to analyze our data with the help of such methods.

Although well developed in several areas of science and industry, especially for dealing with 'big data', the use of ML for clinical oncology has remained limited to date 14,23. In particular, very few studies have investigated ML for prediction of response to immune-checkpoint blockade, and none has focused on the predictive value of blood counts ${ }^{16,24-26}$. In addition, the main limitation of such studies is the small sample size, despite being a critical determinant to ensure the robustness and generalizability of the results ${ }^{27}$. For instance, Wiesweg et al. had 55 patients in the training set and 36 in the test set ${ }^{25}$.

In comparison, we analyzed the data from 298 patients, allowing to have higher statistical power. Training and test sets were thus composed of about 200 and 100 patients in training and tests, respectively. This large number of patients ensured that the models had enough information to learn and predict (Figure S2). Our results even show that 200 patients are sufficient to reach the optimal accuracy, for models with six variables. Importantly, our data was collected from clinical practice (i.e., real-world data), which implies larger heterogeneity but is also more reflective of the reality at bedside ${ }^{22}$. The random forest algorithm emerged as the algorithm with best trade-off over all the metrics considered, resulting in a 68\% mean accuracy and 0.74 mean area under the ROC curve, on test sets. Nevertheless, logistic regression, single layer neural network and naïve Bayes models performed almost equally well, suggesting that similar predictive power can be achieved with a standard, linear statistical learning algorithm such as logistic regression. This is in line with a review that suggested no benefit of ML over logistic regression for clinical prediction models ${ }^{28}$. 
medRxiv preprint doi: https://doi.org/10.1101/2021.11.30.21267064; this version posted December 2, 2021. The copyright holder for this preprint (which was not certified by peer review) is the author/funder, who has granted medRxiv a license to display the preprint in It is made available under a CC-BY-NC-ND 4.0 International license .

Associations between blood count and efficacy were consistent with previous studies, in particularly correlations with hemoglobin, NLR, dNLR and PLR, were the same than in previous studies 5,6,10,11,29. This consistency comforts the interest of pretreatment blood counts for prediction of ICls efficacy. Neutrophils and leukocytes levels were also associated and predictive of response, a finding from our study that has not been reported elsewhere, to our knowledge. We also demonstrated that an ECOG performance status $\geq 2$ was significantly associated with response, a result that remained to be fully established ${ }^{30,31}$. High PS and a high NLR were correlated with worse outcomes, consistently with the physio-pathological immune hypothesis of peripheral lymphocytes stimulation with ICIs, which could lead to redirect TILs to destruct tumor cells through an activation cascade.

The present study focused on the predictive power of blood biomarkers but the model could include additional variables, even if their predictive values are not perfect individually. PD-L1 expression ${ }^{32}$, because of its discordant results, its heterogeneity among histological components ${ }^{33}$ and its poor accuracy when assessed in peripheral blood ${ }^{34}$, is not an ideal predictive biomarker but would probably increase the performance of our model. Some characteristics based on genomic alterations could also be added. Tumor mutational burden (TMB), defined as the total number of nonsynonymous mutations in the tumor exome ${ }^{35}$ and evaluated by next-generationsequencing (NGS), seems to be a potential biomarker ${ }^{36}$. Even if its measure has some limitation such as high cost, large input DNA amount needed and time of analysis, lung cancer is within tumors with the highest TMB ${ }^{37}$, which correlates with $\mathrm{ICl}$ efficacy in NSCLC ${ }^{38}$. Importantly, our results compare favorably with the latter study, where predictive power of (durable) response from PD-L1 expression (AUC $=0.646$ ) or TMB $(A \cup C=0.601)$ was inferior. K-RAS mutation is a frequent genetic alteration with contrasting implications for ICls efficacy. It was initially not linked with poor response to ICls ${ }^{39}$, but a better response when mutated was shown in $2019^{40}$, whereas the cooccurring genomic alteration of K-RAS and STK11/LKB1 was associated with a primary resistance to PD1 axis blockade ${ }^{41}$. Other recent work using metabolomics data obtained from blood sampling demonstrated impressive predictive power of response, although with small sample sizes ${ }^{42,44}$. The integration of such markers in our model might improve its efficacy. Based on the combination of quantitative imaging and machine learning, radiomics study have also started to emerge for prediction of ICls 
medRxiv preprint doi: https://doi.org/10.1101/2021.11.30.21267064; this version posted December 2, 2021. The copyright holder for this preprint (which was not certified by peer review) is the author/funder, who has granted medRxiv a license to display the preprint in It is made available under a CC-BY-NC-ND 4.0 International license.

efficacy from radiological images ${ }^{24,42}$. Such studies should nevertheless be carefully evaluated for their added predictive power in comparison to simpler biomarkers as the ones used here ${ }^{43}$.

The first limitation of our study is the retrospective design and the limited number of centers involved ( 2 centers). Another limitation is the lack of tumor PD-L1 assessment. This testing was not systematically performed from 2013 to 2017 as nivolumab in second-line or more did not require the PD-L1 status to be prescribed to NSCLC patients. This status could have helped our algorithm using a quantitative variable, freeing ourselves from a qualitative threshold as currently used : $1 \%$ for the refund of Durvalumab in France for the maintenance after a radio-chemotherapy or pembrolizumab in second-line therapy ${ }^{44}$ and $50 \%$ for the use of Pembrolizumab in firstline therapy ${ }^{2}$. Nevertheless, the PD-L1 determination methods were not the same as nowadays, involving either a different or biased analysis or a new determination of PDL1 status.

Certain confounding factors such as bacterial and viral infection, demographic variables such as race, recent chemotherapy, or the use of corticosteroids before treatment could have modified the blood counts analyzed in this study. These data were not collected and not analyzed in our study because we wanted a simple tool to help clinical practice, which could benefit to the majority of patients. Furthermore, blood counts were not necessarily sampled the day of first ICls infusion, but sometimes one or some days before. This period of time could also have modified the values. On the other hand, our study reflects clinical practice in real-life.

Eventually, the majority of studies to date, including ours, have focused on static pre-treatment predictive markers. However, dynamic markers that integrate ontreatment data start to emerge, with promising predictive value ${ }^{45}$. In such context, the use of statistical Bayesian modeling is particularly appropriate and holds great promise 46. For ICl, a mathematical model-derived kinetic parameters of tumor kinetics regrowth during relapse has been shown to be the best predictor of overall survival in multivariable analysis including baseline clinical markers ${ }^{47}$. More mechanistic mathematical models for tumor-immune-ICl-radiotherapy dynamics have also been proposed ${ }^{48}$. In light of our results, such models should be applied to include dynamics of blood counts. 
medRxiv preprint doi: https://doi.org/10.1101/2021.11.30.21267064; this version posted December 2, 2021. The copyright holder for this preprint (which was not certified by peer review) is the author/funder, who has granted medRxiv a license to display the preprint in It is made available under a CC-BY-NC-ND 4.0 International license.

\section{CONCLUSION}

Blood counts prior to ICls (elevation of hemoglobin, decrease of NLR, leukocytes or neutrophils) and clinical status (good PS) were significantly associated with better DCR in multivariable analysis. The practical application of these associations using machine learning algorithms was able to predict individual response to treatment. This could be improved further by increasing the number of variables in the model and should be further validated in an independent cohort. 
medRxiv preprint doi: https://doi.org/10.1101/2021.11.30.21267064; this version posted December 2, 2021. The copyright holder for this preprint (which was not certified by peer review) is the author/funder, who has granted medRxiv a license to display the preprint in It is made available under a CC-BY-NC-ND 4.0 International license.

\section{ACKNOWLEDGEMENTS}

The authors would like to thank Pauline Fleury for valuable input on the work. This work is part of the QUANTIC project funded by ITMO Cancer AVIESAN and French Institut National du Cancer (grant \#19CM148-00) 
medRxiv preprint doi: https://doi.org/10.1101/2021.11.30.21267064; this version posted December 2, 2021. The copyright holder for this preprint (which was not certified by peer review) is the author/funder, who has granted medRxiv a license to display the preprint in It is made available under a CC-BY-NC-ND 4.0 International license .

\section{References}

1. Planchard D, Popat S, Kerr K, et al. Metastatic non-small cell lung cancer: ESMO Clinical Practice Guidelines for diagnosis, treatment and follow-up. Ann Oncol 2018;29(Suppl 4):iv192-iv237.

2. Reck M, Rodríguez-Abreu D, Robinson AG, et al. Pembrolizumab versus Chemotherapy for PD-L1-Positive Non-Small-Cell Lung Cancer. $N$ Engl J Med 2016;375(19):1823-1833.

3. Gooden MJM, Bock GH de, Leffers N, Daemen T, Nijman HW. The prognostic influence of tumour-infiltrating lymphocytes in cancer: a systematic review with metaanalysis. Br J Cancer 2011;105(1):93-103.

4. Balkwill F, Mantovani A. Inflammation and cancer: back to Virchow? Lancet 2001;357(9255):539-545.

5. Hopkins AM, Rowland A, Kichenadasse G, et al. Predicting response and toxicity to immune checkpoint inhibitors using routinely available blood and clinical markers. $\mathrm{Br} J$ Cancer 2017;117(7):913-920.

6. Diem S, Schmid S, Krapf M, et al. Neutrophil-to-Lymphocyte ratio (NLR) and Platelet-to-Lymphocyte ratio (PLR) as prognostic markers in patients with non-small cell lung cancer (NSCLC) treated with nivolumab. Lung Cancer Amst Neth 2017;111:176-181.

7. Proctor MJ, McMillan DC, Morrison DS, Fletcher CD, Horgan PG, Clarke SJ. A derived neutrophil to lymphocyte ratio predicts survival in patients with cancer. Br J Cancer 2012;107(4):695-699.

8. Ferrucci PF, Ascierto PA, Pigozzo J, et al. Baseline neutrophils and derived neutrophil-to-lymphocyte ratio: prognostic relevance in metastatic melanoma patients receiving ipilimumab. Ann Oncol 2016;27(4):732-738.

9. Diakos CI, Tu D, Gebski V, et al. Is the derived neutrophil to lymphocyte ratio (dNLR) an independent prognostic marker in patients with metastatic colorectal cancer (mCRC)? Analysis of the CO.17 and CO.20 studies. Ann Oncol [Internet] 2016 [cited 2019 Jul 23];27(suppl_6). Available from:

https://academic.oup.com/annonc/article/27/suppl_6/588P/2799240

10. Gu X, Sun S, Gao X-S, et al. Prognostic value of platelet to lymphocyte ratio in nonsmall cell lung cancer: evidence from 3,430 patients. Sci Rep [Internet] 2016;6. Available from: https://www.ncbi.nlm.nih.gov/pmc/articles/PMC4812293/

11. Mezquita L, Auclin E, Ferrara R, et al. Association of the Lung Immune Prognostic Index with Immune Checkpoint Inhibitor Outcomes in Patients with Advanced Non-Small Cell Lung Cancer. JAMA Oncol 2018;4(3):351-357.

12. Pavan A, Calvetti L, Dal Maso A, et al. Peripheral Blood Markers Identify Risk of Immune-Related Toxicity in Advanced Non-Small Cell Lung Cancer Treated with ImmuneCheckpoint Inhibitors. The Oncologist 2019;

13. Barlesi F, Greillier L, Monville F, et al. LBA53 Precision immuno-oncology for advanced non-small cell lung cancer (NSCLC) patients (pts) treated with PD1/L1 immune checkpoint inhibitors (ICIs): A first analysis of the PIONeeR study. Ann Oncol 2020;31:S1183.

14. Benzekry S. Artificial intelligence and mechanistic modeling for clinical decision making in oncology. Clin Pharmacol Ther 2020;108(3):471-486.

15. Breiman L. Statistical modeling: the two cultures. Stat Sci Rev J Inst Math Stat 2001;16(3):199-231.

16. Ahn B-C, So J-W, Synn C-B, et al. Clinical decision support algorithm based on machine learning to assess the clinical response to anti-programmed death-1 therapy in patients with non-small-cell lung cancer. Eur J Cancer 2021;153:179-189. 
medRxiv preprint doi: https://doi.org/10.1101/2021.11.30.21267064; this version posted December 2, 2021. The copyright holder for this preprint (which was not certified by peer review) is the author/funder, who has granted medRxiv a license to display the preprint in It is made available under a CC-BY-NC-ND 4.0 International license .

17. Eisenhauer EA, Therasse P, Bogaerts J, et al. New response evaluation criteria in solid tumours: Revised RECIST guideline (version 1.1). Eur J Cancer 2009;45(2):228-247.

18. R: The R Project for Statistical Computing [Internet]. [cited 2019 Oct 2];Available from: https://www.r-project.org/

19. Cox DR. Regression Models and Life-Tables. J R Stat Soc Ser B Methodol 1972;34(2):187-202.

20. Therneau TM. A Package for Survival Analysis in R [Internet]. 2021. Available from: https://CRAN.R-project.org/package=survival

21. Kuhn M, Wickham H. Tidymodels: a collection of packages for modeling and machine learning using tidyverse principles. [Internet]. 2020. Available from: https://www.tidymodels.org

22. Becker T, Weberpals J, Jegg AM, et al. An enhanced prognostic score for overall survival of patients with cancer derived from a large real-world cohort. Ann Oncol 2020;31(11):1561-1568.

23. Nicolò C, Périer C, Prague M, et al. Machine Learning and Mechanistic Modeling for Prediction of Metastatic Relapse in Early-Stage Breast Cancer. JCO Clin Cancer Inform 2020;4:259-274.

24. Trebeschi S, Drago SG, Birkbak NJ, et al. Predicting response to cancer immunotherapy using noninvasive radiomic biomarkers. Ann Oncol 2019;30(6):998-1004.

25. Wiesweg M, Mairinger F, Reis $\mathrm{H}$, et al. Machine learning-based predictors for immune checkpoint inhibitor therapy of non-small-cell lung cancer. Ann Oncol 2019;30(4):655-657.

26. Wiesweg M, Mairinger F, Reis H, et al. Machine learning reveals a PD-L1independent prediction of response to immunotherapy of non-small cell lung cancer by gene expression context. Eur J Cancer 2020;140:76-85.

27. Riley RD, Ensor J, Snell KIE, et al. Calculating the sample size required for developing a clinical prediction model. BMJ 2020;368:m441.

28. Christodoulou E, Ma J, Collins GS, Steyerberg EW, Verbakel JY, Van Calster B. A systematic review shows no performance benefit of machine learning over logistic regression for clinical prediction models. J Clin Epidemiol 2019;110:12-22.

29. Zhang Z, Zhang F, Yuan F, et al. Pretreatment hemoglobin level as a predictor to evaluate the efficacy of immune checkpoint inhibitors in patients with advanced non-small cell lung cancer. Ther Adv Med Oncol 2020;12:1758835920970049.

30. Dall'Olio FG, Maggio I, Massucci M, Mollica V, Fragomeno B, Ardizzoni A. ECOG performance status $\geq 2$ as a prognostic factor in patients with advanced non small cell lung cancer treated with immune checkpoint inhibitors-A systematic review and meta-analysis of real world data. Lung Cancer Amst Neth 2020;145:95-104.

31. Krishnan M, Kasinath P, High R, Yu F, Teply BA. Impact of Performance Status on Response and Survival Among Patients Receiving Checkpoint Inhibitors for Advanced Solid Tumors. JCO Oncol Pract 2021;OP.20.01055.

32. Melosky B, Chu Q, Juergens RA, et al. Breaking the biomarker code: PD-L1 expression and checkpoint inhibition in advanced NSCLC. Cancer Treat Rev 2018;65:65-77.

33. Liu Y, Dong Z, Jiang T, et al. Heterogeneity of PD-L1 Expression Among the Different Histological Components and Metastatic Lymph Nodes in Patients With Resected Lung Adenosquamous Carcinoma. Clin Lung Cancer 2018;19(4):e421-e430.

34. Boffa DJ, Graf RP, Salazar MC, et al. Cellular Expression of PD-L1 in the Peripheral Blood of Lung Cancer Patients is Associated with Worse Survival. Cancer Epidemiol Prev Biomark 2017;26(7):1139-1145.

35. Alexandrov LB, Nik-Zainal S, Wedge DC, et al. Signatures of mutational processes in human cancer. Nature 2013;500(7463):415-421. 
medRxiv preprint doi: https://doi.org/10.1101/2021.11.30.21267064; this version posted December 2, 2021. The copyright holder for this preprint (which was not certified by peer review) is the author/funder, who has granted medRxiv a license to display the preprint in It is made available under a CC-BY-NC-ND 4.0 International license .

36. Berland L, Heeke S, Humbert O, et al. Current views on tumor mutational burden in patients with nonsmall cell lung cancer treated by immune checkpoint inhibitors. $J$ Thorac Dis 2018;11(1):S71-S80.

37. Lawrence MS, Stojanov P, Polak P, et al. Mutational heterogeneity in cancer and the search for new cancer genes. Nature 2013;499(7457):214-218.

38. Rizvi H, Sanchez-Vega F, La K, et al. Molecular Determinants of Response to AntiProgrammed Cell Death (PD)-1 and Anti-Programmed Death-Ligand 1 (PD-L1) Blockade in Patients With Non-Small-Cell Lung Cancer Profiled With Targeted Next-Generation Sequencing. J Clin Oncol [Internet] 2018 [cited 2021 Aug 10];Available from: http://ascopubs.org/doi/pdf/10.1200/JCO.2017.75.3384

39. Jeanson A, Tomasini P, Souquet-Bressand M, et al. Efficacy of Immune Checkpoint Inhibitors in KRAS-Mutant Non-Small Cell Lung Cancer (NSCLC). J Thorac Oncol 2019;14(6):1095-1101.

40. Mazieres J, Drilon A, Lusque A, et al. Immune checkpoint inhibitors for patients with advanced lung cancer and oncogenic driver alterations: results from the IMMUNOTARGET registry. Ann Oncol 2019;30(8):1321-1328.

41. Skoulidis F, Goldberg ME, Greenawalt DM, et al. STK11/LKB1 Mutations and PD-1 Inhibitor Resistance in KRAS-Mutant Lung Adenocarcinoma. Cancer Discov 2018;8(7):822835.

42. Sun R, Limkin EJ, Vakalopoulou M, et al. A radiomics approach to assess tumourinfiltrating CD8 cells and response to anti-PD-1 or anti-PD-L1 immunotherapy: an imaging biomarker, retrospective multicohort study. Lancet Oncol 2018;19(9):1180-1191.

43. Welch ML, McIntosh C, Haibe-Kains B, et al. Vulnerabilities of radiomic signature development: The need for safeguards. Radiother Oncol J Eur Soc Ther Radiol Oncol 2019;130:2-9.

44. Herbst RS, Baas P, Kim D-W, et al. Pembrolizumab versus docetaxel for previously treated, PD-L1-positive, advanced non-small-cell lung cancer (KEYNOTE-010): a randomised controlled trial. Lancet Lond Engl 2016;387(10027):1540-1550.

45. Mezquita L, Preeshagul I, Auclin E, et al. Predicting immunotherapy outcomes under therapy in patients with advanced NSCLC using dNLR and its early dynamics. Eur J Cancer Oxf Engl 1990 2021;151:211-220.

46. Kurtz DM, Esfahani MS, Scherer F, et al. Dynamic Risk Profiling Using Serial Tumor Biomarkers for Personalized Outcome Prediction. Cell 2019;178(3):699-713.e19.

47. Claret L, Jin JY, Ferté C, et al. A Model of Overall Survival Predicts Treatment Outcomes with Atezolizumab versus Chemotherapy in Non-Small Cell Lung Cancer Based on Early Tumor Kinetics. Clin Cancer Res 2018;24(14):3292-3298.

48. Serre R, Benzekry S, Padovani L, et al. Mathematical Modeling of Cancer Immunotherapy and Its Synergy with Radiotherapy. Cancer Res 2016;76(17):4931-4940. 


\section{Figures and Tables}

Table 1: Patients and disease characteristics

Figure 1: Exploratory data analysis

Table 2: Logistic regression analysis for disease control

Figure 2: Variable selection

Figure 3: Machine learning algorithms predictive performances

Table 3: Summary of machine learning algorithms predictive performances 


\section{Table 1: Patients and disease characteristics}

\begin{tabular}{|c|c|}
\hline Variable & $\mathrm{N}=298^{1}$ \\
\hline Age & $62(55,69)$ \\
\hline \multicolumn{2}{|l|}{ Sex } \\
\hline Female & $99(33 \%)$ \\
\hline Male & $199(67 \%)$ \\
\hline \multicolumn{2}{|l|}{ Tobacco status } \\
\hline Former Smoker & $140(47 \%)$ \\
\hline Non smoker & $36(12 \%)$ \\
\hline Smoker & $122(41 \%)$ \\
\hline Brain metastases & $72(29 \%)$ \\
\hline \multicolumn{2}{|l|}{ Performance status } \\
\hline$>=2$ & $26(8.9 \%)$ \\
\hline $0-1$ & $265(91 \%)$ \\
\hline \multicolumn{2}{|l|}{ Mutation profile } \\
\hline ALK & $1(0.8 \%)$ \\
\hline BRAF & $9(7.4 \%)$ \\
\hline EGFR & $14(11 \%)$ \\
\hline KRAS & $87(71 \%)$ \\
\hline Other mutation & $5(4.1 \%)$ \\
\hline ROS1 & $2(1.6 \%)$ \\
\hline Wild type & $4(3.3 \%)$ \\
\hline \multicolumn{2}{|l|}{ Immunotherapy type } \\
\hline anti-CTLA-4 & $3(1.0 \%)$ \\
\hline anti-PD-1 & $266(89 \%)$ \\
\hline anti-PD-L1 & $26(8.7 \%)$ \\
\hline Combination & $3(1.0 \%)$ \\
\hline \multicolumn{2}{|l|}{ Previous treatment } \\
\hline Chemotherapy & $281(95 \%)$ \\
\hline Chemotherapy + immunotherapy & $5(1.7 \%)$ \\
\hline Targeted therapy & $11(3.7 \%)$ \\
\hline \multicolumn{2}{|l|}{ Response } \\
\hline Complete response & $2(0.7 \%)$ \\
\hline Partial response & $44(15 \%)$ \\
\hline Progressive disease & $131(45 \%)$ \\
\hline Stable disease & $113(39 \%)$ \\
\hline
\end{tabular}

${ }^{1}$ Median (IQR); n (\%) 
Figure 1: Exploratory data analysis

A
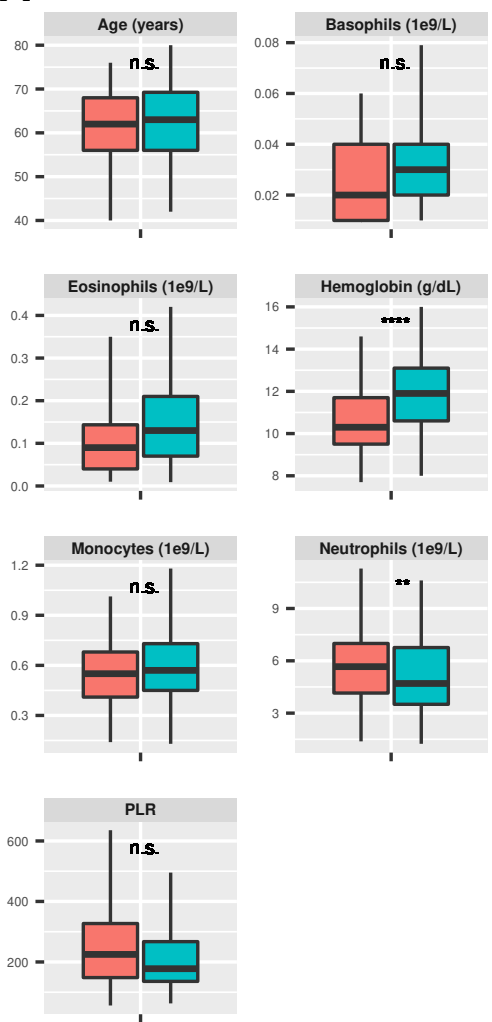

B
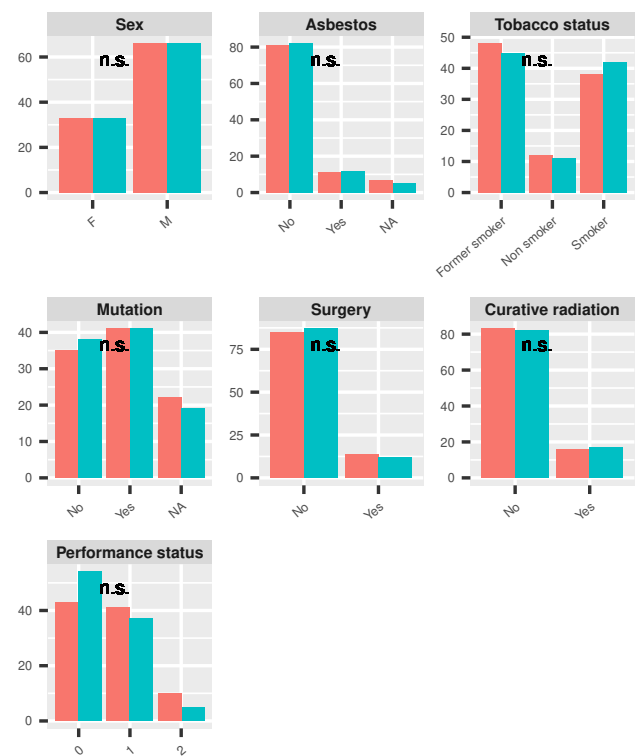

Response $\mathrm{PD}$

\section{A. Boxplots of continuous variables \\ B. Barplots of categorical variables}

$\mathrm{BMI}=$ body mass index, NLR = neutrophils-to-lymphocytes ratio, $\mathrm{PLR}=$ platelets-to-lymphocytes ratio, $\mathrm{CR}=$ complete response, $\mathrm{PR}=$ partial response, $\mathrm{SD}=$ stable disease and $\mathrm{PD}=$ progressive disease. Stars indicate statistical significance: ${ }^{*}=\mathrm{p}<0.05,{ }^{* *}=\mathrm{p}<0.01,{ }^{* * *}=\mathrm{p}<0.001,{ }^{* \star * *}=\mathrm{p}<0.0001$, n.s. $=$ non significant. 
Table 2: Logistic regression analysis for disease control

\begin{tabular}{|c|c|c|c|c|c|c|}
\hline \multirow[b]{2}{*}{ Variable } & \multicolumn{3}{|c|}{ Univariable logistic regression } & \multicolumn{3}{|c|}{ Multivariable logistic regression } \\
\hline & Odds ratio $[95 \% \mathrm{IC}]$ & $\mathrm{p}$ & signif & Odds ratio $[95 \%$ IC] & $\mathrm{p}$ & signif \\
\hline Lymphocytes & $1.1[0.83,1.4]$ & 0.678 & & $0.98[0.15,5.2]$ & 0.984 & \\
\hline NLR & $0.49[0.31,0.73]$ & 0.000879 & $* * *$ & $0.68[0.098,1.9]$ & 0.651 & \\
\hline Platelets & $1[0.82,1.3]$ & 0.762 & & $1.3[0.72,2.4]$ & 0.404 & \\
\hline PLR & $0.84[0.64,1.1]$ & 0.156 & & $1.1[0.5,2.4]$ & 0.788 & \\
\hline Leukocytes & $0.68[0.5,0.89]$ & 0.00791 & ** & $0.6[0.0022,3 \mathrm{e}+02]$ & 0.847 & \\
\hline Hemoglobin & $1.9[1.5,2.5]$ & $9.26 \mathrm{e}-07$ & $\star \star \star *$ & $1.8[1.3,2.4]$ & 0.000122 & $\star \star \star *$ \\
\hline dNLR & $0.63[0.47,0.83]$ & 0.00155 & ** & $0.8[0.33,2.7]$ & 0.689 & \\
\hline Neutrophils & $0.62[0.45,0.83]$ & 0.00232 & ** & $1.5[0.0047,2.7 \mathrm{e}+02]$ & 0.863 & \\
\hline Monocytes & $0.87[0.69,1.1]$ & 0.226 & & $0.86[0.5,1.4]$ & 0.545 & \\
\hline Eosinophils & $1.3[0.97,1.9]$ & 0.139 & & $1.1[0.75,1.8]$ & 0.582 & \\
\hline Basophils & $1.2[0.95,1.8]$ & 0.177 & & $1.2[0.89,1.8]$ & 0.321 & \\
\hline BMI & $1.2[0.95,1.5]$ & 0.123 & & $1[0.76,1.3]$ & 0.997 & \\
\hline Performance status & $0.5[0.39,0.64]$ & $6.21 \mathrm{e}-08$ & $* * *$ & $0.58[0.44,0.75]$ & $7.79 \mathrm{e}-05$ & *** \\
\hline
\end{tabular}


Figure 2: Variable selection

A

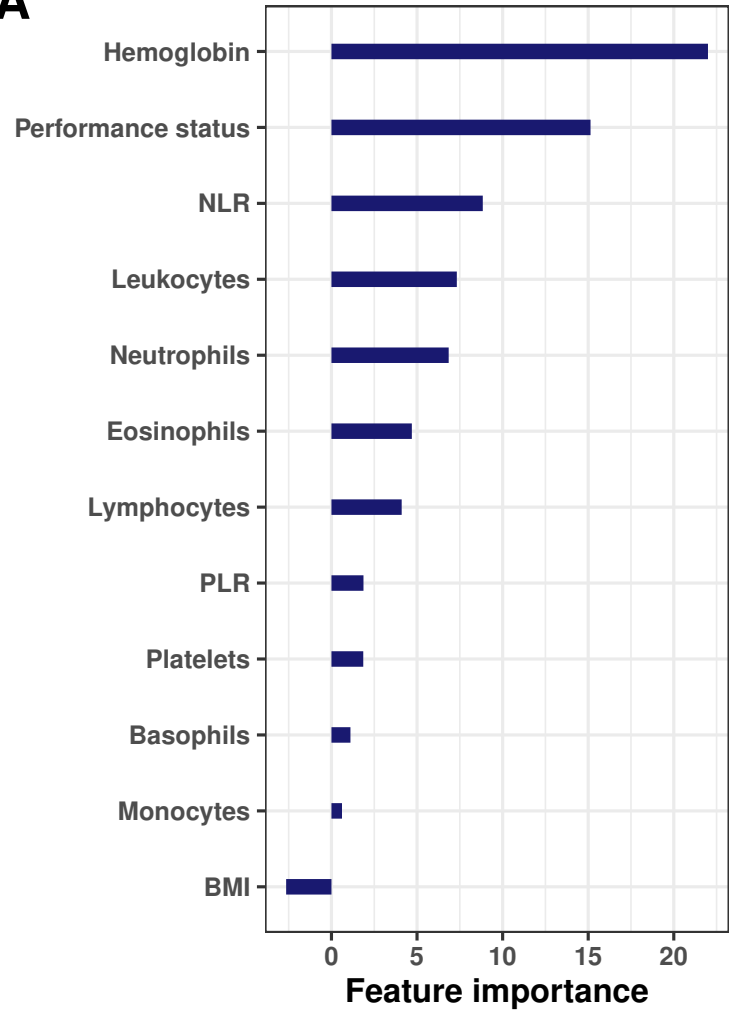

B

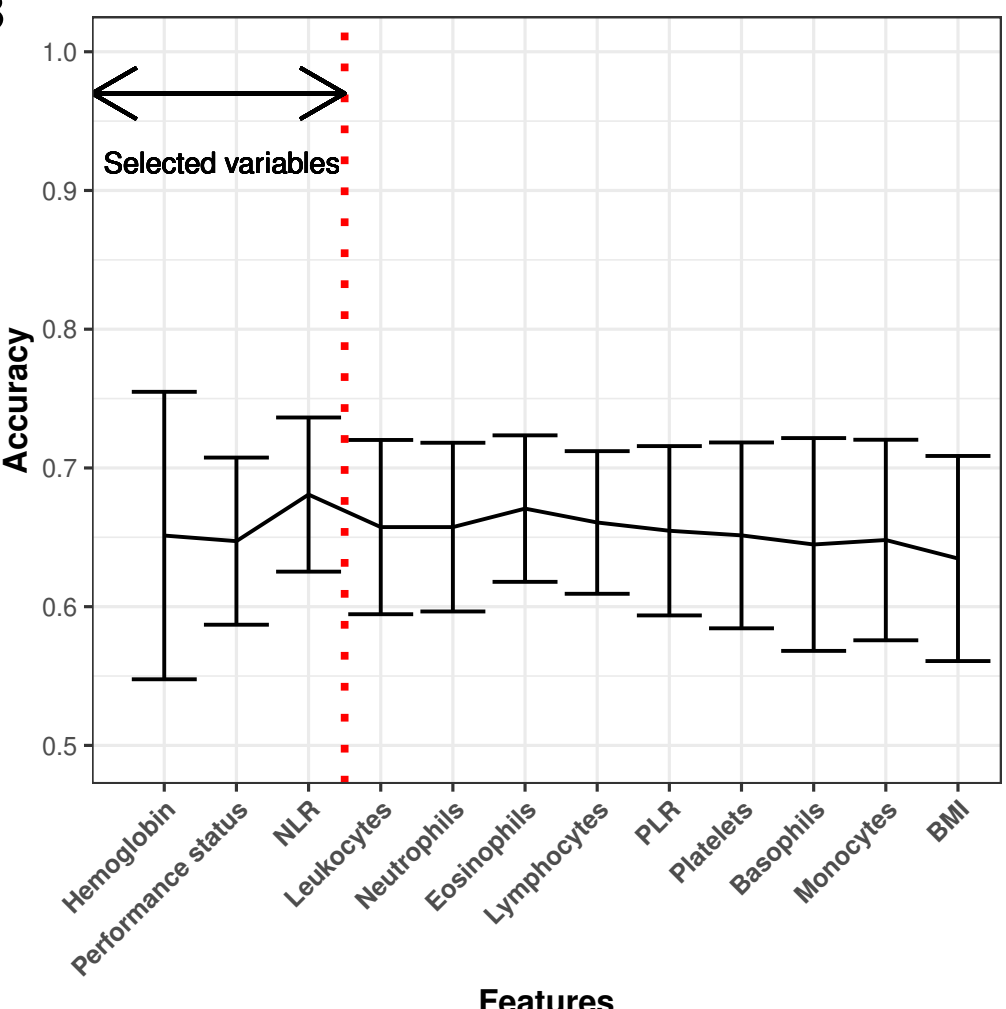

A. Feature importance based on random forest classification and mean decrease in accuracy.

B. Accuracy score of incremental logistic regression models built on an increasing number of predictors (i.e., the first one contains only hemoglobin, the second hemoglobin and NLR, etc..).

$\mathrm{NLR}=$ neutrophils-to-lymphocytse ratio. $\mathrm{PLR}=$ platelets-to-lymphocytes ratio. $\mathrm{BMI}=$ body mass index 
Figure 3: Machine learning algorithms predictive performances
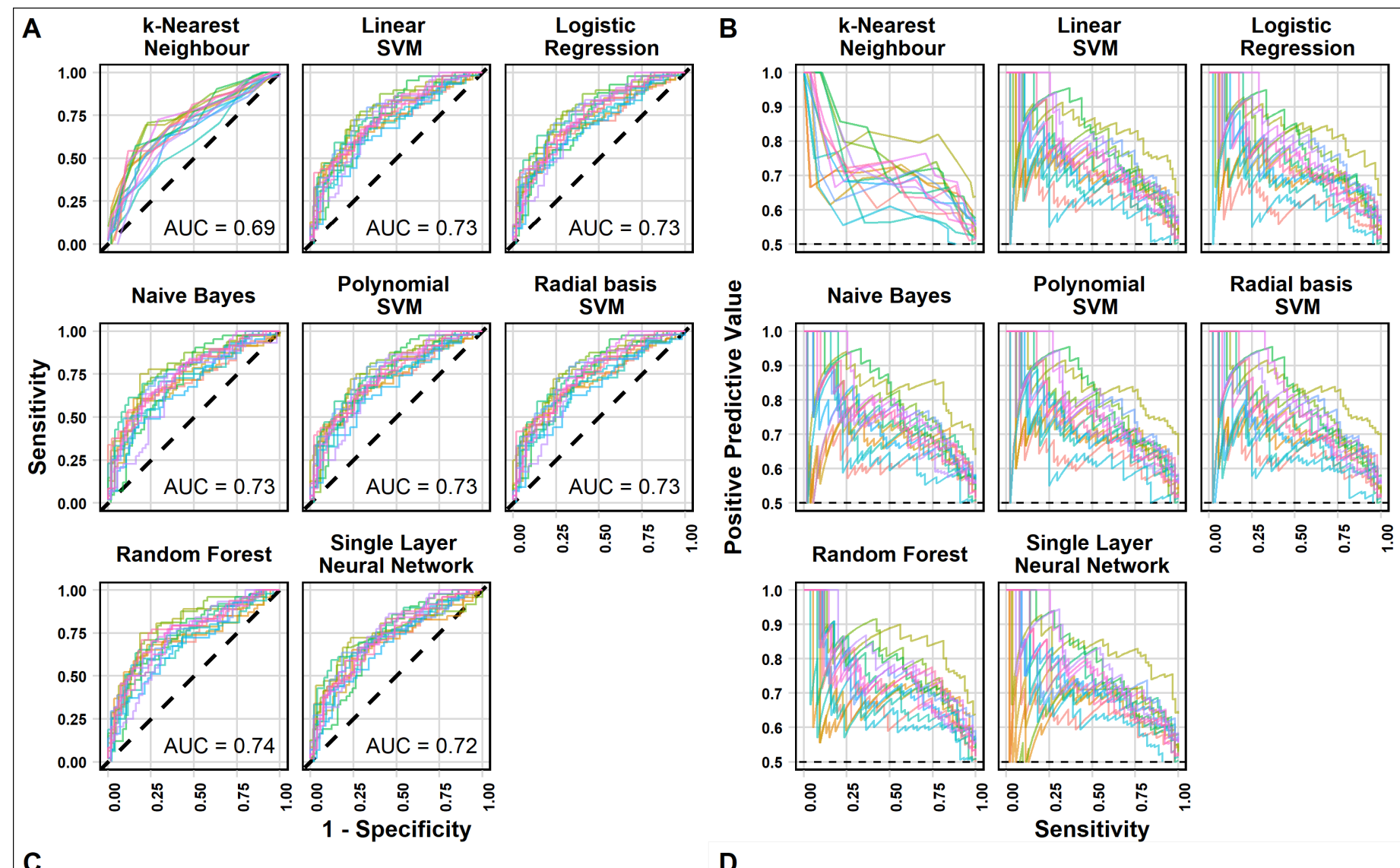

SVM

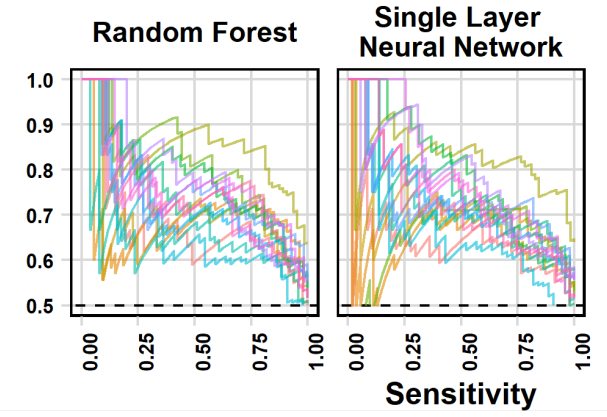

C
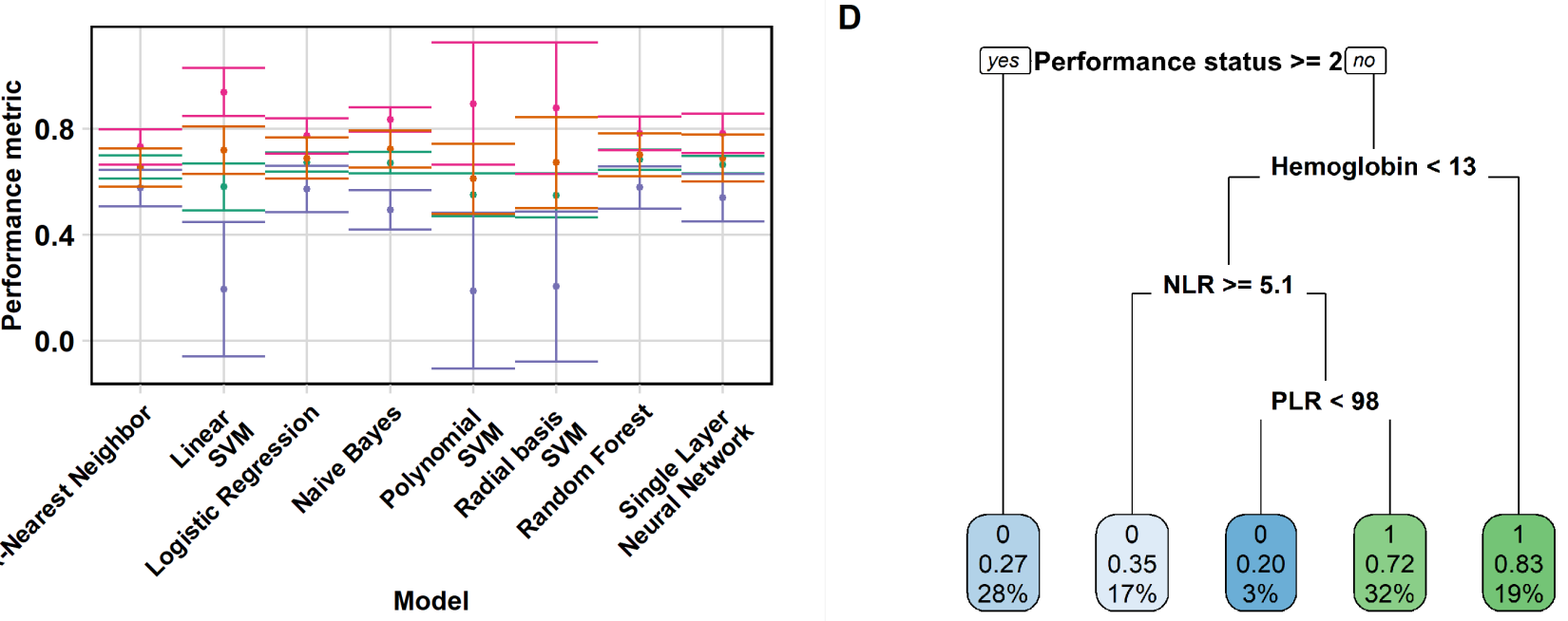

Metric $\rightarrow$ Accuracy $\rightarrow$ Precision $\rightarrow$ Sensitivity $\rightarrow$ Specificity

A. Receiver-operator curves for prediction on test sets from each fold of the outer cross-validation loop, for each model. $\mathrm{AUC}=$ area under the curve.

B. Precision (positive-predictive value) - recall (sensitivity) curves.

C. Main performance metrics for each algorithm.

D. Decision tree obtained after tuning and training. Each node shows: the predicted class $(0=P D, 1=C R+P R+S D)$, the predicted probability of response and the percentage of total observations in the node. $\mathrm{PD}=$ progressive disease, $\mathrm{CR}=$ complete response, $\mathrm{PR}=$ partial response, $\mathrm{SD}=$ stable disease. 
Table 3: Summary of machine learning algorithms predictive performances

\begin{tabular}{|c|c|c|c|c|c|c|}
\hline Model & Accuracy & ROC AUC & PPV & NPV & Sensitivity & Specificity \\
\hline Random Forest & $0.68 \hat{A} \pm 0.04$ & $0.74 \hat{A} \pm 0.03$ & $0.70 \hat{A} \pm 0.08$ & $0.68 \hat{A} \pm 0.06$ & $0.58 \hat{A} \pm 0.08$ & $0.78 \hat{A} \pm 0.06$ \\
\hline $\begin{array}{l}\text { Logistic } \\
\text { Regression }\end{array}$ & $0.67 \hat{A} \pm 0.04$ & $0.73 \hat{A} \pm 0.03$ & $0.69 \hat{A} \pm 0.08$ & $0.67 \hat{A} \pm 0.06$ & $0.57 \hat{A} \pm 0.09$ & $0.77 \hat{A} \pm 0.07$ \\
\hline Naive Bayes & $0.67 \hat{A} \pm 0.04$ & $0.73 \hat{A} \pm 0.03$ & $0.72 \hat{A} \pm 0.07$ & $0.65 \hat{A} \pm 0.06$ & $0.49 \hat{A} \pm 0.07$ & $0.83 \hat{A} \pm 0.05$ \\
\hline $\begin{array}{l}\text { Single Layer } \\
\text { Neural Network }\end{array}$ & $0.66 \hat{A} \pm 0.03$ & $0.72 \hat{A} \pm 0.03$ & $0.69 \hat{A} \pm 0.09$ & $0.66 \hat{A} \pm 0.06$ & $0.54 \hat{A} \pm 0.09$ & $0.78 \hat{A} \pm 0.07$ \\
\hline $\begin{array}{l}\text { k-Nearest } \\
\text { Neighbour }\end{array}$ & $0.66 \hat{A} \pm 0.04$ & $0.69 \hat{A} \pm 0.04$ & $0.65 \hat{A} \pm 0.07$ & $0.66 \hat{A} \pm 0.06$ & $0.58 \hat{A} \pm 0.07$ & $0.73 \hat{A} \pm 0.07$ \\
\hline Linear SVM & $0.58 \hat{A} \pm 0.09$ & $0.73 \hat{A} \pm 0.03$ & $0.72 \hat{A} \pm 0.09$ & $0.58 \hat{A} \pm 0.10$ & $0.19 \hat{A} \pm 0.25$ & $0.94 \hat{A} \pm 0.09$ \\
\hline $\begin{array}{l}\text { Polynomial } \\
\text { SVM }\end{array}$ & $0.55 \hat{A} \pm 0.08$ & $0.73 \hat{A} \pm 0.03$ & $0.61 \hat{A} \pm 0.13$ & $0.58 \hat{A} \pm 0.13$ & $0.19 \hat{A} \pm 0.29$ & $0.89 \hat{A} \pm 0.23$ \\
\hline $\begin{array}{l}\text { Radial basis } \\
\text { SVM }\end{array}$ & $0.55 \hat{A} \pm 0.08$ & $0.73 \hat{A} \pm 0.03$ & $0.67 \hat{A} \pm 0.17$ & $0.56 \hat{A} \pm 0.06$ & $0.20 \hat{A} \pm 0.28$ & $0.88 \hat{A} \pm 0.25$ \\
\hline
\end{tabular}




\section{Supplementary figures and tables}

Table S1: Blood counts at ICI treatment start

Figure S1: Progression-free and overall survival

Table S2: Cox regression: progression-free survival

Table S3: Cox regression: overall survival

Figure S2: Learning curves 
Table S1: Blood counts at ICI treatment start

\begin{tabular}{lcccc}
\hline Variable & Mean & Median & Min & Max \\
\hline Basophils & 0.04 & 0.03 & 0.00 & 0.80 \\
Derived NLR & 3.15 & 2.37 & 0.41 & 18.58 \\
Eosinophils & 0.16 & 0.11 & 0.00 & 3.26 \\
Hemoglobin & 11.32 & 11.30 & 7.30 & 16.40 \\
Leucocytes & 8.56 & 7.99 & 2.09 & 49.65 \\
Lymphocytes & 1.55 & 1.35 & 0.11 & 19.31 \\
Monocytes & 0.63 & 0.58 & 0.07 & 1.96 \\
Neutrophils & 6.17 & 5.52 & 0.86 & 46.00 \\
NLR & 5.66 & 3.85 & 0.46 & 96.91 \\
Platelets & 317 & 290 & 57 & 2,013 \\
PLR & 273 & 214 & 3 & 2,309 \\
\hline
\end{tabular}


Figure S1: Progression-free and overall survival

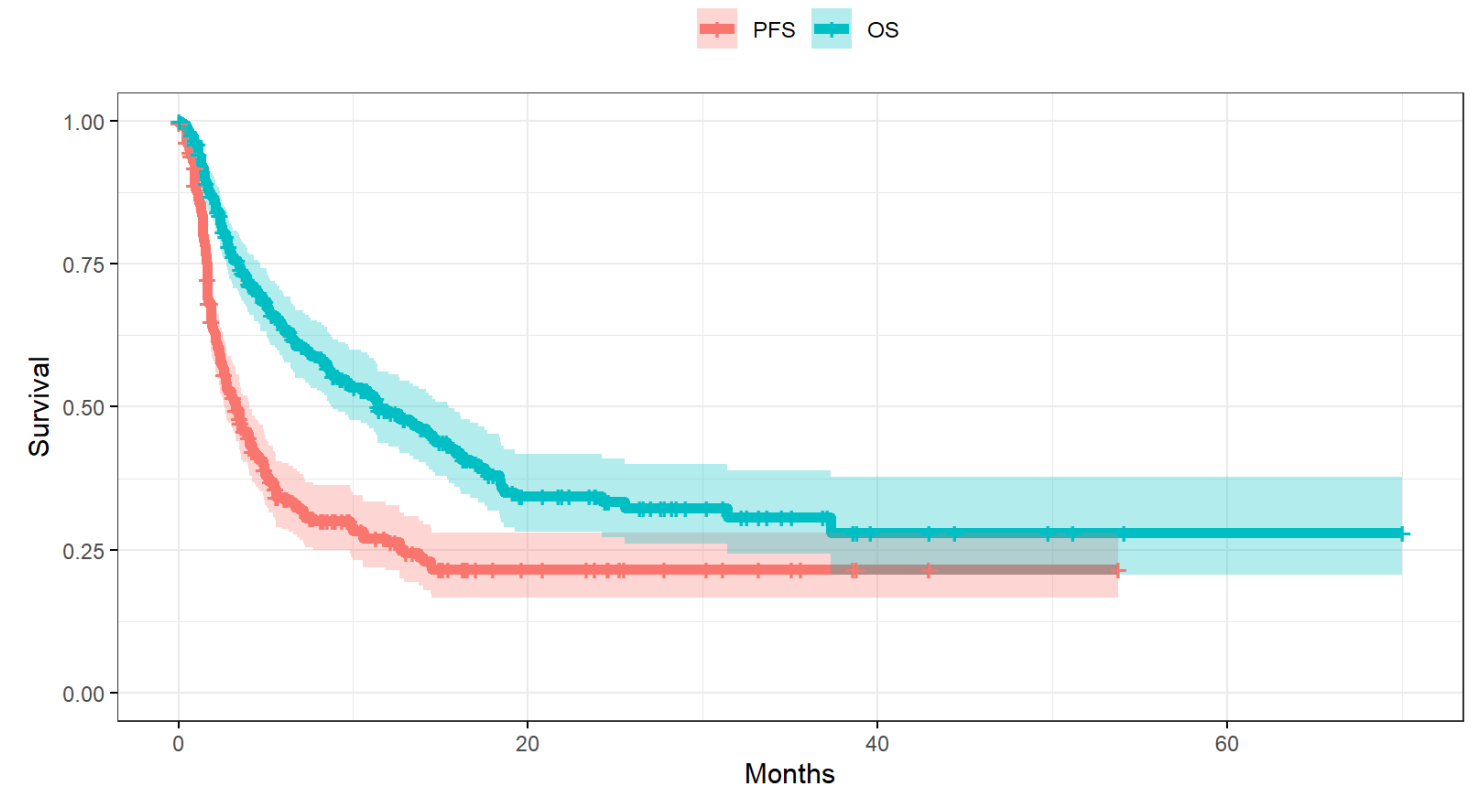

Number at risk

\begin{tabular}{ccccc|}
\hline PFS & 18 & 2 & 0 \\
\hline 298 & 43 & 6 & 1 \\
\hline 0 & 20 & Months & 40 & 60 \\
\hline
\end{tabular}




\section{Table S2: Cox regression: progression-free survival}

\begin{tabular}{|c|c|c|c|c|c|c|}
\hline \multirow[b]{2}{*}{ Variable } & \multicolumn{3}{|c|}{ Univariable cox regression } & \multicolumn{3}{|c|}{ Multivariable cox regression } \\
\hline & Hazard ratio $[95 \%$ IC] & $\mathrm{p}$ & signif & Hazard ratio $[95 \%$ IC] & $\mathrm{p}$ & signif \\
\hline Lymphocytes & $0.85[0.71,1]$ & 0.0912 & . & $1[0.38,2.6]$ & 0.996 & \\
\hline NLR & $1[1,1]$ & 0.00585 & ** & $0.71[0.33,1.5]$ & 0.376 & \\
\hline Platelets & $1[1,1]$ & 0.37 & & $0.81[0.59,1.1]$ & 0.206 & \\
\hline PLR & $1[1,1]$ & 0.881 & & $1[0.66,1.5]$ & 0.994 & \\
\hline Leukocytes & $1.1[1,1.1]$ & 0.00246 & ** & $0.69[0.044,11]$ & 0.795 & \\
\hline Hemoglobin & $0.9[0.83,0.97]$ & 0.00525 & $* *$ & $0.84[0.72,0.98]$ & 0.0291 & * \\
\hline $\mathrm{dNLR}$ & $1.1[1,1.1]$ & 0.0017 & $* *$ & $1.2[0.69,1.9]$ & 0.596 & \\
\hline Neutrophils & $1.1[1,1.1]$ & $6.26 \mathrm{e}-05$ & *** & $2[0.15,26]$ & 0.603 & \\
\hline Monocytes & $1.1[0.66,1.8]$ & 0.774 & & $1[0.78,1.3]$ & 0.885 & \\
\hline Eosinophils & $0.53[0.23,1.2]$ & 0.138 & & $0.96[0.77,1.2]$ & 0.695 & \\
\hline Basophils & $0.91[0.14,6.1]$ & 0.923 & & $0.99[0.87,1.1]$ & 0.917 & \\
\hline BMI & $0.96[0.93,0.99]$ & 0.0133 & * & $0.88[0.76,1]$ & 0.088 & \\
\hline Performance status & $2.1[1.6,2.9]$ & $8.15 \mathrm{e}-07$ & $* * *$ & $1.3[1.1,1.5]$ & 0.000335 & $* * *$ \\
\hline
\end{tabular}


Table S3: Cox regression: overall survival

\begin{tabular}{|c|c|c|c|c|c|c|}
\hline \multirow[b]{2}{*}{ Variable } & \multicolumn{3}{|c|}{ Univariable cox regression } & \multicolumn{3}{|c|}{ Multivariable cox regression } \\
\hline & Hazard ratio $[95 \%$ IC $]$ & $\mathrm{p}$ & signif & Hazard ratio $[95 \%$ IC] & $\mathrm{p}$ & signif \\
\hline Lymphocytes & $0.8[0.64,0.99]$ & 0.045 & * & $1.1[0.4,3.1]$ & 0.845 & \\
\hline NLR & $1[1,1.1]$ & $4.54 \mathrm{e}-08$ & $* * *$ & $0.87[0.43,1.7]$ & 0.686 & \\
\hline Platelets & $1[1,1]$ & 0.81 & & $0.83[0.58,1.2]$ & 0.305 & \\
\hline PLR & $1[1,1]$ & 0.331 & & $1[0.65,1.6]$ & 0.949 & \\
\hline Leukocytes & $1.1[1,1.1]$ & $6.63 e-07$ & *** & $0.99[0.054,18]$ & 0.994 & \\
\hline Hemoglobin & $0.83[0.76,0.91]$ & $3.58 \mathrm{e}-05$ & *** & $0.76[0.64,0.92]$ & 0.00392 & $* *$ \\
\hline dNLR & $1.2[1.1,1.2]$ & $8.93 e-09$ & *** & $1.4[0.83,2.2]$ & 0.225 & \\
\hline Neutrophils & $1.1[1.1,1.1]$ & $4.05 e-10$ & *** & $1.3[0.087,19]$ & 0.857 & \\
\hline Monocytes & $1.4[0.85,2.3]$ & 0.195 & & $1.1[0.82,1.5]$ & 0.558 & \\
\hline Eosinophils & $0.13[0.032,0.54]$ & 0.00509 & ** & $0.78[0.55,1.1]$ & 0.166 & \\
\hline Basophils & $0.72[0.071,7.4]$ & 0.784 & & $0.99[0.84,1.2]$ & 0.943 & \\
\hline BMI & $0.97[0.93,1]$ & 0.0715 & . & $0.93[0.8,1.1]$ & 0.405 & \\
\hline Performance status & $2.8[2,3.9]$ & $1.12 \mathrm{e}-09$ & *** & $1.4[1.2,1.6]$ & $3.68 \mathrm{e}-05$ & $* * *$ \\
\hline
\end{tabular}


Figure S2: Learning curves

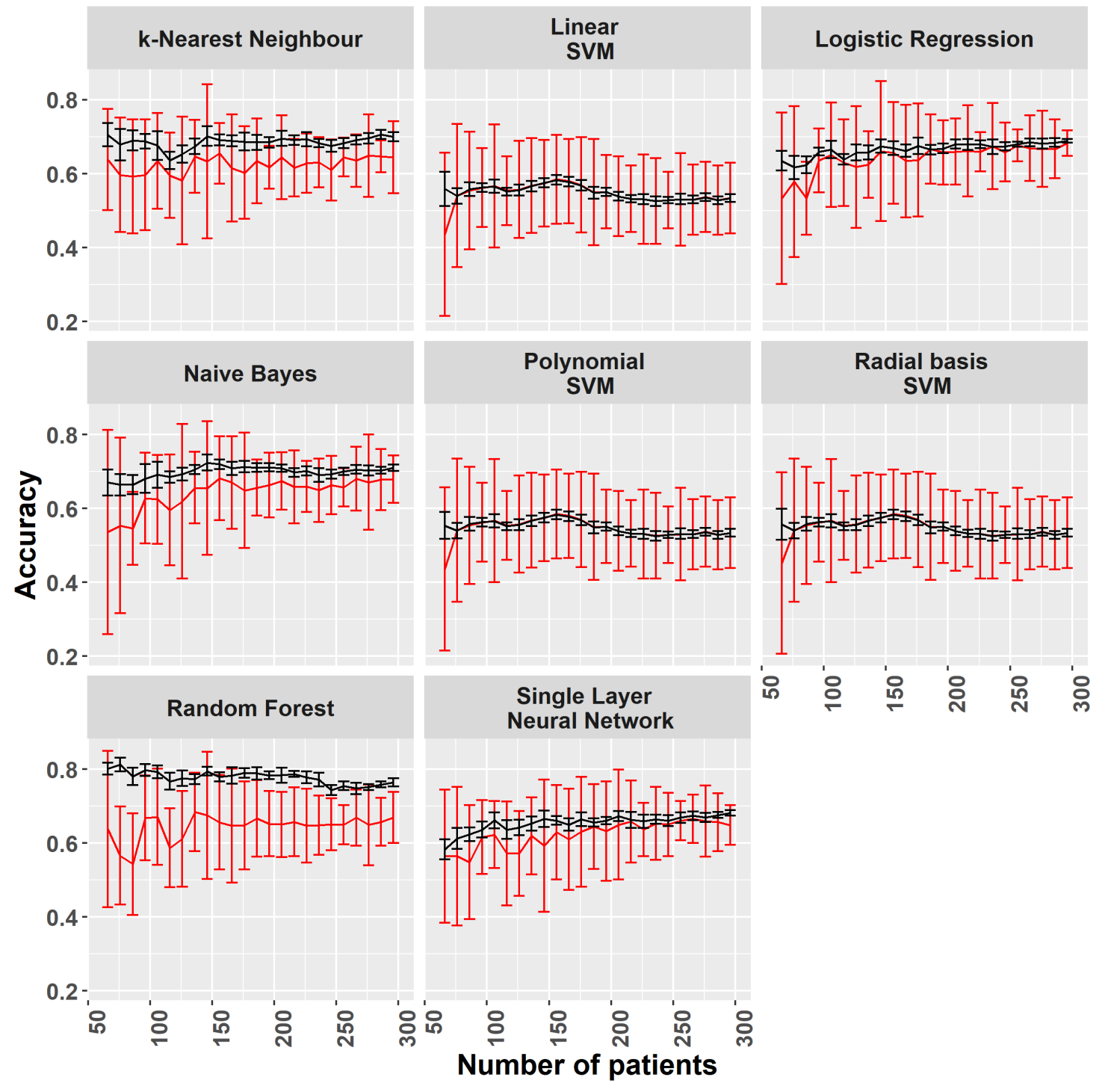

